DIGITALCOMMONS

@WAYNESTATE —
Michigan Journal of Counseling:

Research, Theory and Practice

Volume 34 | Issue 1

Article 4

5-1-2007

\title{
Teaching a Doctoral Course in Consultation: The Parallel Team Process
}

\author{
Arnold B. Coven \\ Wayne State University, aa1553@wayne.edu \\ Jennifer Araujo \\ Wayne State University \\ Katherine G. Van Hull \\ Wayne State University \\ Shedeh Tavokoli-Moayed \\ Wayne State University \\ Ann Collins \\ Wayne State University \\ See next page for additional authors
}

Follow this and additional works at: https://digitalcommons.wayne.edu/mijoc

\section{Recommended Citation}

Coven, A. B., Araujo, J., Van Hull, K. G., Tavokoli-Moayed, S., Collins, A., Enwiya, J., \& Boyes, K. (2007). Teaching a Doctoral Course in Consultation: The Parallel Team Process, Dimensions of Counseling, 34(1), 14-20. doi:10.22237/mijoc/1177977780

This Article is brought to you for free and open access by the Open Access Journals at DigitalCommons@WayneState. It has been accepted for inclusion in Michigan Journal of Counseling: Research, Theory and Practice by an authorized editor of DigitalCommons@WayneState. 


\section{Teaching a Doctoral Course in Consultation: The Parallel Team Process}

\section{Authors}

Arnold B. Coven, Jennifer Araujo, Katherine G. Van Hull, Shedeh Tavokoli-Moayed, Ann Collins, Jina Enwiya, and Kathleen Boyes 
According to French and Bell (1999), an important characteristic of organizational consultants is interpersonal competence. Similarly, Yalom (1995) highlighted the importance of interpersonal relationships in group work. Counselors are well equipped to improve the performance of organizational groups because they are well trained in relationship skills and group dynamics. However, counselor education students often lack opportunities to practice and generalize their interpersonal group counseling skills. Through group discussions, the course instructor (senior author) determined that many graduate counseling students believe they lack knowledge about organizational functioning, and therefore are hesitant to approach human service agencies or business organizations for consulting opportunities. One explanation for this lack of confidence may be attributed to counseling practicum and internship classes that typically do not include consulting work experiences.

The purpose of the doctoral course in consultation was to teach and demonstrate how students could use group and individual counseling skills in organizational consultation. The design of this course was to present organizational consultation theory, principles, and techniques to the students using weekly seminars and, most importantly, to provide an experiential consulting component. This would supply the students with an opportunity to utilize their developing knowledge and acquired skills by performing organizational consultation for an agency that was experiencing difficulties in its organization.

The class project began when a student team member telephoned the director of an Assertive Community Treatment (ACT) unit, a community mental health program $(\mathrm{CMH})$ in the Midwest, and asked if the unit would be willing to have a group of doctoral students provide consultation. Typically, ACT teams in $\mathrm{CMH}$ programs consist of individuals from a variety of professions, often reflecting distinct disciplinary and/or social cultures. The challenge for these professionals is to combine their knowledge in order to work closely together to create solutions for persons with severe and persistent mental illness (SPMI) living in the community. Allred, Burns, and Phillips (2005) state, "an effective ACT team operates as a single unit of expertise that continuously organizes and reorganizes itself in response to client needs" (p. 213). One barrier to widespread implementation of ACT units is the lack of attention given to organizational team dynamics: Communication, decision-making, and / or leadership (Corrigan, Steiner, McCracken, Blaser, \& Barr, 2001).

The director of the ACT unit was interested in improving the performance of two of the agency's ACT teams and responded affirmatively. Thus, the consultation task was to facilitate the performance of

these teams. It was decided to place the students in two teams so they could experience what it was like to develop an effective team. Although not originally planned, having two teams became the stimulus for teaching the teamwork process on two levels simultaneously. At this point, the class became a working organization which would be helping another working organization. This would provide learning on two levels, and students could see their own group issues parallel to those in the agency. It was hoped that both class groups would grow toward higher team performance and would use their knowledge of group theory, process, techniques, and therapeutic factors to work as teams who could assist the organizational teams to become cohesive and wellfunctioning.

\section{Parallel Process}

An additional educational purpose that was not planned but became an important factor was the increased awareness of parallel learning structures. The theory is that when teams work together, they mirror each other, and understanding this process helps increase the functioning and effectiveness of teams. Smith and Zane (1999) advise consultants to self reflect on how their own behavior mirrors the behaviors to be changed. When two systems have significant relationships with each other, they frequently develop similar affects, cognitions, and behaviors (Aldefer, Brown, Kaplan, \& Smith, 1990). These parallel processes can begin in several ways and influence relationships between individuals and groups. Thus, understanding the parallel process between student and organizational teams can facilitate recognition of team dynamics and promote development of appropriate interventions. Student teams that can talk about and recognize their process can work more effectively with consultee teams who may be experiencing similar processes. This communication and process recognition was the essence of the parallel team process that guided the doctoral consultation class. 


\section{Teamwork}

Today, many social service organizations are utilizing and empowering work teams to improve organizational functioning. Katzenbach and Smith (1993) identified several important team building concepts: 1) smaller groups operate more effectively and efficiently; 2 ) identified purposes and goals provide direction for a team; 3) identification of personal competencies (technical, problem solving and interpersonal) enable team members to choose roles that fit; 4) mutual accountability promotes equal sharing of work assignments; and 5) commitment leads to fulfillment of the goals. Experts believe that work teams can be the building foundations of organizations (French \& Bell, 1999). The predominant view is that teams need to manage their relationships and work processes to be effective. The assumption is that when work teams are empowered, performance as well as work satisfaction is increased and performance is greater. Hackman and Oldham (1980) indicate that self-managed work teams are a powerful social invention, and in a moderately supportive organizational context, they can accomplish significant alterations in work performance and organizational management.

The helpful elements that enable teams to function effectively are similar to Yalom's (1995) group therapeutic factors. Team members need to understand their tasks and goals and share their knowledge and training, which can be likened to imparting information. When the team members share their common knowledge and experience, it is similar to universality. Team members responding to each other is more effective than learning alone, similar to the feedback process in group counseling. Team members encouraging and stimulating each other resembles the instillation of hope that group members need to motivate each other. Team members need to broaden attitudes and values that develop the skills and commitment to work together and do jobs well, which can be compared to the social skills and interpersonal competence emphasized in group counseling. Learning how to do a job well affects team members' views of themselves, similar to the identity development and empowerment that occurs in groups. When team members help each other in these ways, altruism supports group members' team effort and performance. When these therapeutic factors operate in teams, cohesiveness, which is needed for high performance, develops. The following are the group skills which enable teams to operate effectively: Staying in the present, using "I," talking directly to each other, encouraging participation of all group members, giving and receiving feedback, processing how the group works together, and identifying individual and group goals.

\section{Consultation Stages}

Throughout the consultation stages of entry, diagnoses, intervention, and evaluation, the student teams were able to study and monitor their own team functioning as well as the organizational teams.

\section{Entry}

During the initial meeting, the student team members identified the information and tasks

needed to guide the consultation. They agreed that the important steps included: (1) developing a working relationship; (2) learning the history of the agency and the departmental structure; (3) gaining an understanding of the organization's culture; and (4) assisting management and the teams to identify areas that needed improvement.

The overall goal was to help the ACT teams and the $\mathrm{CMH}$ administration learn to identify and solve their own problems. Using a collaborative consultation model, the students perceived the consultees as experts and worked to develop an egalitarian relationship with them. This followed Hanson, Himes, and Meier's (1990) recommendation that the first step in consultation is to define the consultant and consultee relationship. Redmon, Cullari, and Farris (1985) highlighted the importance of identifying all organization levels in the consultation process and assuring all are represented. In addition, the researchers recommended individual, confidential sessions for all levels, during which the nature of the consultation process is communicated.

Structurally, the ACT department was comprised of two teams. Each team had six case managers. Both teams were led by one supervisor and the department director. The doctoral consultant teams planned individual interviews with the director and supervisor, and all the consultee team members. These steps would hopefully facilitate the establishment of open relationships that would promote the sharing and identification of team struggles and conflicts. The doctoral students planned to continue the consultation process with group meetings for more problem identification, feedback, and intervention strategies.

A critical event surfaced in the first meeting with the director of the ACT team. She seemed uncomfortable being in a small room with four new people. She moved the meeting to a larger room and asked the Assertive Community Treatment (ACT) supervisor to join the group. These actions surprised the consulting team because the new location did not provide privacy, compromised confidentiality, and interfered with the team's plan for individual interviews. The data gathering process was interrupted by several agency employees 
who walked in and out of the room and overheard management discuss concerns about the ACT teams. As a result, several employees looked at the consultant team members suspiciously, as if they were conspiring with agency

management. In retrospect, the consultant team could have asked that the meeting be moved to a more private area. The director and the supervisor may have then disclosed more, and the trust level that the consultants needed to develop with team members might have been supported.

The student consultants learned that the purpose of the ACT program was to help persons with mental illness maintain emotional stability and adjust to community life. The director and the supervisor outlined the agency's needs: 1) to increase the ACT teams' problem solving abilities and cohesiveness; 2) to increase the team members' ability to protect themselves while working with clients who were occasionally threatening; 3 ) to increase the personal and professional growth of the case managers; and 4) to decrease the teams' dependence on supervision.

In the initial interviews with ACT members it was learned that there was a lack of clarity about the purpose of the consultation, the team leaders, and the nature of their roles. The consultants also discovered that the ACT members had been told the consultation was related to nursing, not organizational development. One team leader was a case manager who also attended administrative meetings. Her dual role was confusing to the team members. In a parallel manner, the student consultation teams were also perplexed. They did not know who would be the team members or leaders in their own groups, making it unclear how they would interact and share the workload. Group and individual goals had not been identified. This may be attributed to the teams' lack of experience, which caused anxiety and uncertainty.

The student teams observed that one ACT team was more interactive and effective than the other. One team's members were eager to help and support each other, while the other team experienced interpersonal difficulties, reportedly with members working separately from one another. An actual partition dividing the members of this team physically created a communication barrier.

A process similar to the agency's groups was observed among the class teams. While one student team's members worked well together, sharing responsibilities and rotating leadership, the other team's members struggled to communicate without being misunderstood. One student did not believe that she had a role on the team, and another perceived some team members as not sharing information. Each team chose one team leader, which caused conflict, because several students had leadership abilities and struggled with the chosen leader's team management. Some members did not actively participate in the discussions or in doing their share of the work. Beginning recognition of the parallel process facilitated the students' deeper understanding about team conflict and motivated a search for problem-solving interventions.

\section{Problem/Strength Identification}

The student consultation teams decided to use the term "problem identification," as opposed to diagnosis, which usually relates to mental health services rather than organizational functioning. They also focused on identifying the strengths and opportunities within the organization. This identification process began with entry and did not end until evaluation because consultants can identify problems, strengths, and possible interventions within every phase of consultation.

While gathering data about the history, culture, and goals of the organization, the class teams discovered the agency administering the program had changed from a county service to a private non-profit mental health facility. Stress, anxiety, and safety were critical issues related to the difficult population the organization served. Job security was also a concern, because reduced funding had resulted in several layoffs and high worker turnover. Similar to the organizational teams, several students from the consultation teams expressed frustration and anxiety about the doctoral program. The university was experiencing a budget crisis, which had reduced the number of counselor education faculty. Students believed there were not enough professors to provide different perspectives, advice, or feedback. These similar feelings and reactions of the students and ACT members were further illustrations of the parallel process.

The director and supervisor of the ACT teams readily gave time to the consultation project. Their effort demonstrated that management as well as employees were motivated and recognized a need for change. Most ACT members showed a similar willingness and 
motivation by making themselves available for interviews, despite several ACT team members' skepticism about whether the consultation would be successful. The consultees' cooperation with the student consultants was identified as a strength of the organization.

The doctoral student teams also evaluated their cooperation and commitment to the consultation project. They questioned whether team members would be willing to schedule meetings outside the university setting. One member stated he had limited time outside of class to visit the agency and conduct an individual interview. He requested permission to do a telephone consultation. The professor rejected this request, because it could convey less importance to the organizational team member and undermine the other students' efforts. Although several agreed with the professor's action, his authoritarian decision triggered team tension. Both the student and organizational teams were dealing with issues of motivation and commitment. The recognition of these parallel concerns maximized the students' learning process.

Overall, several ACT members felt insufficiently prepared to work with their clients. A major fear related to safety issues working with potentially violent clients who could possess weapons. Some members stated they would feel safer working in pairs or wearing a device with a panic button. Many requested additional training in selfdefense and physical management techniques. In parallel fashion, the student teams verbalized concern about their ability to apply consultation theory within an organization. One student stated, "I am not certain if I have sufficient knowledge of consultation," and another student indicated, "I know how to counsel, but to take on the role of a consultant is unfamiliar ground." It was helpful for team members to learn that others were experiencing the same feelings (universality). At this point, the professor underlined that obtaining experiential knowledge would assist them in learning how to generalize their counseling skills to organizational consultation. This helped allay their doubts and increased hope that they could help these teams and the agency.

After summarizing the data, attention was focused on the difficulties and strengths within the organization. The concerns identified were: 1) understaffed teams; 2) insufficient time and space to debrief from crisis experiences; and 3) lack of clerical support for the heavy paper workload, decreasing interaction with clients. Some organizational (ACT) team members did not object to the new time requirement for computer input of client information, while others thought it was time consuming, tedious, and an added stressor in their daily workload. The areas perceived positively were: 1) communication among (ACT) team members; 2) supervisor support; 3) positive feedback between members; and 4) commitment to the program and population the group served. There was consensus that their work with clients was meaningful and goal directed.

Like the ACT teams, student difficulties and strengths were also reviewed. Problem identification included: 1) difficulties with sharing information; 2) leadership struggles; 3 ) feelings of exclusion; and 4) time constraints. The strengths were: 1) mutual goals; 2) freedom to disagree; 3) energy to resolve problems; 4) students' establishment of an e-mail network facilitating communication; and 5) recognition of doubts about their confidence.

\section{Interventions}

All planned activities that occurred during the stages of entry, problem identification and evaluation are considered interventions. Following the individual interviews, group meetings were implemented with each ACT team separately. Specific group interventions utilized during this consultation process included team building activities, such as giving and receiving corrective feedback and "Sharing Appreciation and Concerns." Members voiced appreciation for each other's help and support during their daily activities and crisis situations. Examples of their reinforcing statements were: "good job" and "that sounds like a great idea." These positive reactions enhanced feelings of recognition and cohesiveness. They expressed respect for each other's working styles and wanted more opportunities to share their approaches with each other. These group appreciation exercises increased the likelihood the ACT team members would share more in the future and contribute to a climate of team support.

In a parallel fashion, the two class teams repeated some of the same interventions: Giving and receiving feedback, and sharing thoughts and concerns. An exercise in which members formed a circle and threw a ball to one another was suggested by one team and was conducted during class. The receiver would tell the thrower what was respected and valued about the group member. One student paused and could not devise a positive statement about another group member. She stated, "I don't feel as though you are committed to this group." The student was able to receive that honest feedback constructively and was able to reevaluate his role in the group.

Through consultation, the ACT teams and administrators (supervisor and director) were learning how to identify their own problems and strengths. This experience may have enabled them to consider their own interventions in the future to improve team functioning and program effectiveness. Larson and Mafasto (1989) underlined the 
need for administrative support and leadership. Therefore, the students developed a summary report and met with the program director and supervisor to review the progress of the consultation. The feedback provided opportunities for administration to validate data, increase their awareness of teams' issues, and develop solutions.

Following these meetings, the two doctoral student teams and the course professor met with the two ACT teams, the program director and supervisor, in one large group.

The purpose was to share the consultants' findings about the ACT program's needs and strengths, to discuss the intervention recommendations, and prepare tentative plans for implementation. In this meeting, the ACT members gave feedback to each other, and shared concerns such as safety issues. This process appeared to reduce communication barriers, increase group unity and morale, and the group collaboration gave the students a sense of accomplishment in their consultation project. Most importantly, the students appeared to learn the process and techniques of developing solutions and building team cohesiveness.

\section{Evaluation}

Evaluation of the effects of a parallel team approach to teaching and conducting consultation required a systematic gathering of information. It was an ongoing process applied throughout the consulting process and concluded with evaluation of outcomes. Learning about process and outcome evaluation required several primary skills for both the student and organizational teams: 1 ) the ability to monitor the team process; 2) the ability to monitor their role within the team; 3 ) the ability to identify intervention outcomes; and 4) the ability to establish criteria for change and goal attainment.

Process evaluation of all the teams revealed parallel concerns, particularly during the entry and problem identification stages. Both student and organizational teams struggled with issues of belonging, communication, member/leader role confusion, lack of clear consultation goals, conflicting schedules, and authority issues. As a result of looking at the parallel process, the students learned more about team and organizational dynamics. They learned the value of open communication, giving and receiving feedback, the importance of monitoring their own group processes, and thus were empowered to develop interventions that addressed parallel team problems.

Outcome evaluation identified the changes resulting from consultation. The administration and organizational teams made several substantive changes. These included: 1) increasing safety training sessions; 2) instituting monthly ACT staff meetings; 3) implementing bonuses and merit raises; and 4) securing funds for the entire ACT program staff to attend the national ACT conference. A dramatic event occurred when one team's members removed the partition in their office that had previously created a physical and communicative barrier. Despite the fact that empirical data were not collected, the process and outcome changes fulfilled the original consultation goals of increased team effectiveness and cohesiveness.

On the other hand, some recommendations were not implemented. For example, the ACT teams wanted a more efficient documentation system. The program director and supervisor shared the constraining rules governing all mental health programs funded by the state. Thus, the ACT teams were able to accept that changes in the documentation system were not possible. Although this problem was not solved, the discussion increased the organizational teams' understanding of the difficulties faced by the director and supervisor.

Congruently, changes occurred within the doctoral consultation teams. The students learned early in the project that their communication breakdown threatened the success of the consultation project. Due to varying class schedules and job responsibilities, several students felt excluded from the important information and decision-making processes within the teams. One positive outcome was the group's ability to listen to an alienated team member's frustration about not belonging. This member stated, "I don't feel close to anyone." Listening and open communication were two interventions that led to his sense of inclusion. After this student voiced dissatisfaction, the team was able to identify other members experiencing the same feelings. The ball throwing exercise opened communication barriers and shed light on difficulties between members. This led to the member stating, "I feel closer to this group." These examples demonstrate how student teams similar to the organizational teams developed problem-solving interventions without suggestions from outside sources. 


\section{Parallel Team Process of Teaching Consultation: Discussion and Recommendations}

To perform a more empirical evaluation, a pre and post likert type assessment instrument could be employed. The doctoral students, consultees, and administration would assess their knowledge of consultation and teamwork before and after the consultation. The same groups, as well as the professor, would also rate the effectiveness of the consultation. Desirably, the groups would be open to doing the outcome measure six months later to assess whether effects persisted or were helping them in the present.

The parallel team learning process enabled the students to identify similar behaviors occurring in the ACT teams and the class consultation teams. The students increased their learning about group interpersonal dynamics, and both teams were able to discover and implement their own interventions for team building and growth, which seemed to increase self-esteem and team empowerment.

The professor utilized several critical team-building elements for evaluation of the parallel team teaching project. One, the class consultation teams of five met the standard of being small enough to operate effectively and efficiently. Two, although the class team's members were clear that the goal was to assist in the improvement of the two agency teams, several purposes were not stated: to operate effectively as a team; to monitor the team members' own learning process; to perform well; to obtain a superior grade (A); and finally, for each team member to make a unique individual contribution to the team. Greater awareness of these purposes may have increased the teams' effectiveness. Typically, the purposes provide the direction and goals for a team.

Three, the key team building element of commitment was met in varying degrees by the class teams. Recognizing positive changes in the agency from the consultation project increased the students' commitment. It is recommended that professors, administrators, and team members monitor the ongoing process to increase commitment. Four, it is also critical that members are chosen on the basis of their complementary abilities and not on compatibility or status (Katzenbach \& Smith, 1993). Greater attention could have been focused on this teambuilding element. If the professor had identified the skills needed for the project, such as technical, problemsolving, decision-making and interpersonal skills, the prospective team members may have chosen more appropriate team roles. When deciding on the roles, tasks, and goals, it is important that each function require an equivalent amount of work, since student resentment is typical when a member relies on others to do the work. It is recommended that the team discuss these matters, and that each member share how he or she will be accountable to the team.

Gutkin and Curtis (1982) suggested that consultation models are comprised of two goals. One is to focus on existing problems, and the other is to increase consultees' skills so they can be effective in the future. These dual goals identified by these experts were congruent with the consultation project: To assist the agency with its present problems, and to train members to manage their organizational difficulties in the future. Similarly, the learning experience increased the doctoral students' consulting and group skills and empowered them to become future counselor/ consultants.

\section{References}

Aldefer, C. P., Brown, L. D., Kaplan, R. G., \& Smith, K. K. (1990). Group relations and organizational diagnosis. New York: Wiley.

Allred, C. A., Burns, B. J., \& Phillips, S. D. (2005). The assertive community treatment team as a complex dynamic system of care. Administration and Policy in Mental Health, 32(3), 211-220.

Corrigan, P. W., Steiner, L., McCracken, S. G., Blaser, B., \& Barr, M. (2001). Strategies for disseminating evidence-based practices to staff who treat people with serious mental illness. Psychiatric Services, 52(12), 1598-1606.

Council for Accreditation of Counseling and Related Educational Programs. (2001). CACREP accreditation manual: 2001 standards. Alexandria, VA: Author.

Davis, K. M. (2003). Teaching a course in school-based consultation.

Counselor Education and Supervision, 42, 275-282. French, W. L., \& Bell, C. H., Jr. (1999). Organizational development. Upper Saddle, N.J.: Prentice Hall.

Gutkin, T. B., \& Curtis, M. J. (1982). School-based consultation. In C. R. Reynolds \& T. B. Gutkin (Eds.), The handbook of school psychology. New York: Wiley.

Hackman, J. R., \& Oldham, G. R. (1980). Work redesign. Reading, MA: Addison-Wesley.

Hanson, J. C., Himes, B. S., \& Meier, S. (1990). Consultation concepts and practices. New Jersey: Prentice-Hall.

Katzenbach, J. R., \& Smith, D. K. (1993). The wisdom of teams. Boston: Harvard Business School.

Larson, C. E., \& Mafasto, F. M. J. (1989). Team work. Newbury Park, CA: Sage.

Morrill, W. H., Oetting, E. R., \& Hurst, J. C. (1974). Dimensions of counselor functioning. Personnel and Guidance Journal, 52, 354-359.

Redmon, W. K., Cullari, S., \& Farris, H. E. (1985). An analysis of some important risks and phases in consultation. Journal of Community Psychology, 13, 375-385.

Shullman, S. (2002). Reflections of a consulting counseling psychologist: Implications of the principles for education and training at the doctoral and postdoctoral level in consulting psychology for the practice of counseling psychology. Consulting Psychology Journal: Practice and Research, 54(4), 242-251.

Smith, K., \& Zane, N. (1999). Organizational reflections: Parallel process at work in a dual consultation. Journal of Applied Behavioral Science, 35(2), 145-162.

Yalom, I. D. (1995). The theory and practice of group psychotherapy $\left(4^{\text {th }}\right.$ ed.). New York: Basic Books. 